\title{
DEL BUEN USO DE LAS MURALLAS IBÉRICAS
}

\author{
POR
}

\author{
PIERRE MORET
}

\section{RESUMEN - RÉSUMÉ}

A propósito de un artículo reciente, reflexiones sobre la función de las fortificaciones ibéricas.

À propos d'un article récent, réflexions sur la fonction des fortifications ibériques.

\section{PALABRAS CLAVE - MOTS CLÉS}

Cultura Ibérica. Segunda Edad del Hierro. Fortificaciones.

Iberian Culture. Second Iron Age. Fortifications.

En un artículo publicado en el anterior número de Gladius, Francisco Gracia Alonso me hace el honor de citarme como único representante de las tesis que «han tenido como última consecuencia la negación del uso bélico de las fortificaciones, tomando como base teórica para ello la imposibilidad de que las mismas pudieran ser ni tan sólo objeto de ataque en función de los recursos técnicos y tácticos propios de las estructuras sociales ibéricas (Moret, 1996)» ${ }^{1}$. Mi primera reacción fue preguntarme quién sería ese arqueólogo homónimo mío, quien tiene opiniones tan disparatadas sobre las fortificaciones ibéricas. ¡Cuál no fue mi sorpresa cuando me dí cuenta, al consultar la bibliografía del artículo de F. Gracia, que se trataba de mí!

Responder a un dictamen crítico es un ejercicio que puede revestir cierto interés cuando existe, por parte del crítico, una verdadera comprensión y una valoración ponderada de la tesis puesta en tela de juicio. Se abren entonces las posibilidades de un diálogo fructífero. La tarea es más estéril cuando lo que se reprocha a uno difiere completamente de lo que ha escrito. En tales casos, lo único que se puede hacer es rectificar. Esto es lo que voy a intentar en las siguientes líneas, pidiendo disculpas al lector por verme obligado a repetir (en forma resumida y traducida al castellano) argumentaciones y observaciones ya publicadas ${ }^{2}$.

F. Gracia me atribuye «la negación del uso bélico de las fortificaciones» y la convicción de que éstas no pudieron ser «ni tan sólo objeto de ataque». No se refiere a ninguna página concreta de mi tesis, y esto no es de extrañar, pues jamás pensé ni escribí semejantes dilates. No insisto, puesto que los aspectos estrictamente militares y defensivos de las fortificaciones ibéricas son los que he tratado con más detalles, tanto a partir de las fuentes literarias (Fortif.

1 F. Gracia Alonso, «Análisis táctico de las fortificaciones ibéricas», Gladius, 20, 2000, p. 131-170 (frase citada en p. 131).

2 P. Moret, Les fortifications ibériques, de la fin de l'âge du Bronze à la conquête romaine, Madrid, Casa de Velázquez, 1996 (en adelante: Fortif. ib.). 
ib., p. 34-38, 242-255 y 261-262) como desde la arqueología (ibid. passim, y conclusiones p. 262-263). Ahora bien, la vital importancia de la fortificación como medio de defensa en absoluto es incompatible con otras funciones que confieren a las murallas un complejo significado social, político y hasta religioso (ibid., p. 265-293).

Dice también el autor, p. 136: «En contra de las tesis que indican que las torres de los sistemas defensivos ibéricos tenían tan sólo una función de vigía para prevenir ataques por sorpresa o razzias, consideradas como la única forma en que un ejército ibero podría expugnar una ciudad dados sus limitados recursos militares (Moret, 1996), el estudio arquitectónico de las fortificaciones indica lo contrario». Otra imputación sin fundamento. Resumo aquí las páginas que he dedicado a esta cuestión (Fortif. ib., p. 116-120).

La torre es sin duda un elemento característico de los poblados amurallados ibéricos. Se documentan torres en más de $60 \%$ de las 87 fortificaciones mejor conocidas de las fases antigua y plena de la cultura ibérica (siglos VI a III a. C.). Sin embargo, esta cifra encubre una realidad compleja y variada. Se considera habitualmente que el flanqueo (es decir, la posibilidad de alcanzar el flanco del asaltante desde un puesto avanzado por delante de la muralla, cruzando estos disparos laterales con los disparos frontales de los defensores situados en la propia muralla) es la función principal de las torres. Un sistema de flanqueo generalizado necesita un número elevado de torres, situadas de trecho en trecho a lo largo de la muralla. Este tipo de fortificaciones es muy minoritario entre los iberos (25\% de las murallas con torres). Además, excepto en el caso de Ullastret, los intervalos entre las torres son muy irregulares (por ejemplo, de 12 a 30 metros en Puente Tablas). Mucho más frecuentes (40\%) son las murallas que poseen torres solamente en el sector de acceso, generalmente en un lado o en los dos lados de la puerta principal. En estos casos, el principio táctico del flanqueo se limita a la defensa de la entrada.

Es de destacar que la existencia de sistemas de flanqueo extensos o completos en algunas fortificaciones ibéricas no es una consecuencia de la revolución poliorcética acaecida en el Mediterráneo central a principios del siglo IV. Curiosamente, los ejemplos ibéricos mejor conocidos son mucho más antiguos: finales del siglo VI en el Puig de Sant Andreu de Ullastret (Girona), pleno siglo VI en Puente Tablas (Jaén). No se aprecia un aumento significativo de las fortificaciones con flanqueo generalizado durante el Ibérico Pleno. Al contrario, en un caso tan emblemático como el de Ullastret, se observa un claro retroceso en este aspecto. En las defensas del sector del Istmo del Puig de Sant Andreu, construidas durante el siglo IV, la única torre existente se situa en el extremo de la cortina, sin flanquearla. La ausencia de torres de flanqueo en este sector no se compensa por el trazado en seudo-cremallera de la muralla, ya que sólo existe un ángulo importante (con entrada de tres metros) en 140 metros de cortina.

Obviamente, la cuestión del papel de las torres dista mucho de agotarse con la noción táctica del flanqueo. Existen como mínimo otras seis posibles funciones.

1) Refuerzos arquitectónicos. Así se explicaría el emplazamiento de muchas torres, aberrante desde un punto de vista defensivo pero muy efectivo si se toma en cuenta una función de contrafuerte.

2) Plataformas de defensa. Algunos bastiones grandes, situados cerca de un acceso o de un punto vulnerable, están idealmente conformados para ser utilizados como lugares de concentración de los defensores en caso de asalto.

3) Cuerpos de guardia, ocupados de forma permanente. Me refiero aquí a torres situadas al lado de una puerta, con espacio habitable en la planta baja.

4) Torres-atalayas, en lugares destacados cerca de una entrada o en la parte más alta del recorrido de la fortificación. 
5) Torres para emisión de señales luminosas. Aunque siempre faltarán las pruebas, no se puede descartar esta hipótesis, defendida hace algunos años por E. Díes Cusí3.

6) Torres como elemento de prestigio y símbolo de fuerza y poder. No hace falta insistir en este aspecto, de todos conocido. Sólo recalcar que no es ninguna casualidad si Tito Livio (XXII, 19, 6) y Polibio (teste Estrabón, III, 4, 13) utilizaron la sinécdoque de la torre (turris, purgos) para designar los pequeños poblados fortificados de la Hispania de fines del siglo III y principios del II (cf. Fortif. ib., p. 152-153).

Resumiendo: el flanqueo formó parte de los criterios que intervinieron en la concepción de las fortificaciones ibéricas, pero no fue el más importante; además, cuando se puso en práctica, raras veces lo fue de forma ortodoxa y con resultados tácticamente eficaces. En fin, su evolución en Iberia tuvo un ritmo propio, en modo alguno acompasado con los progresos técnicos y tácticos de la poliorcética helenística.

En cambio, la especialización de muchas torres ibéricas en papeles de vigilancia y/o protección de las entradas constituye una respuesta perfectamente adecuada a una tradición bélica que privilegia el factor sorpresa y prefiere un asalto repentino al costoso despliegue de un asedio en regla. Con ello no quiero decir que los asedios no existiesen entre los iberos; en un tema como éste hay que evitar las generalizaciones, teniendo en cuenta la diversidad de las situaciones regionales (Fortif. ib., p. 263). Caso aparte sería el de la Turdetania, donde evidencias de todo índole hacen pensar que, por lo menos durante el siglo III, las concepciones tácticas llegaron a acercarse significativamente a lo que se conocía en el Mediterráneo Central. Sin lugar a dudas, las fortificaciones complejas de los grandes oppida andaluces no se insertan en el mismo contexto bélico que los pequeños recintos del Bajo Aragón, del interior de Cataluña o de las sierras murcianas.

Las conclusiones de F. Gracia sobre estos aspectos son muy distintas. Su razonamiento arraiga en la idea según la cual los tratados técnicos griegos de Eneas el Táctico y de Filón de Bizancio «constituyen puntos de partida correctos para el análisis de la concepción táctica del uso de las fortificaciones en la cultura ibérica» (p. 156-157). Si entiendo bien el sentido de la expresión «punto de partida», esta afirmación supone la existencia de un influjo griego muy concreto, no solamente en el campo de las formas aquitectónicas, sino también en el campo de la poliorcética y de la ingeniería militar. En otras palabras, el autor postula la existencia de una amplia koiné tecnológico-militar, difundida a lo largo de los siglos IV y III en todo el Mediterráneo, Iberia incluida. De hecho, según F. Gracia, «las tribus ibéricas, a fines del siglo III a. C. ${ }^{4}$, conocían los sistemas fundamentales de defensa contra el empleo de máquinas de guerra» (p. 155). Para aceptar estas aseveraciones, se necesitaría lógicamente la comprobación de dos hechos: 1/ que los tratados militares helenísticos, o las ideas contenidas en ellos, eran conocidos en la clase dirigente de las ciudades ibéricas, y $2 /$ que los iberos practicaban asedios al estilo helenístico, usando cercos, zapas, artificios varios y artillería de máquinas de torsión. Ambas cosas son indemostrables. Una acumulación abigarrada de citas de todas épocas y de excursus sobre los asirios, los cartagineses ${ }^{5}$, Homero o la guerra de Cien Años, no pueden paliar la falta de evidencias.

3 E. Díes Cusí, «Funcionalidad de las torres en las fortificaciones del Camp de Turia (Valencia): defensa, vigilancia y señales», Fortificacions - la problemàtica de l'ibèric ple (segles IV-III a. C.). Simposi Internacional d'Arqueologia Ibèrica (Manresa, 1990), Manresa, 1991, p. 175.

4 La mención de las fortificaciones de Ullastret, Turó del Montgròs y Les Toixoneres en otra frase que expresa la misma idea (p. 141) implicaría una fecha inicial del siglo IV para la introducción en Iberia de las máquinas de guerra.

5 ¿De qué sirven tantas referencias al asedio de Cartagena, si los sitiadores eran romanos y los sitiados cartagineses (p. 139 y 140-141)? Sólo pueden crear confusión, sobre todo cuando se alude a la artillería de Cartagena en medio de una argumentación a favor de la existencia de máquinas arrojadizas en el armamento ibérico (p. 141). Se podría decir lo mismo de muchos párrafos dedicados a las técnicas poliorcéticas utilizadas por Aníbal durante el sitio de Sagunto (p. 151-154). Sobre este asedio, Fortif. ib., p. 242-255, y F. Romeo Marugán y J. I. Garay Toboso, «El asedio y toma de 
Para empezar, las fuentes literarias están totalmente mudas en cuanto a la experiencia poliorcética ${ }^{6}$ de los iberos. No describen ningun asedio realizado por ejércitos ibéricos ${ }^{7}$. En cambio, si analizamos en Tito Livio ${ }^{8}$ las descripciones del comportamiento de los iberos sitiados por ejércitos romanos o púnicos, la impresión que se desprende es la de una respuesta inadecuada o improvisada (Fortif. Ib., p. 261-262). El desfase es táctico y técnico a la vez. En el campo táctico, vemos en varias ocasiones como la respuesta indígena se limita a buscar combate en campo raso después de una salida masiva, no porque los sitiados no confiarían en sus murallas, sino, más probablemente, porque la batalla campal en terreno abierto - con todas sus implicaciones ideológicas - era la noción clave y la culminación irremisible de su concepto de la guerra. El ejemplo más significativo es el del asedio de la capital de los lacetanos en 195. De forma repentina, los sitiados abren la puerta del oppidum y salen impetuosamente $^{9}$, dejando la ciudad inerme, vacía de defensores. Pero también se puede citar la salida masiva de los defensores de Astapa en 206 (Liv., XXVIII, 22, 11). En estos bruscos esfuerzos para romper el cerco, sin preparación adecuada y sin movimientos de diversión, los astapenses y los lacetanos se revelan (en los dos extremos de la geografía ibérica) irreprimiblemente reacios a la forma de guerra estática que les era impuesta por la poliorcética romana.

En cuanto al armamento, se empleó una gran variedad de armas en la defensa de las plazas fuertes ibéricas, pero sin llegar jamás al grado de especialización y de complejidad que supone F. Gracia. Las únicas armas realmente especializadas mencionadas en las fuentes son las horcas (furcae) y los ganchos o «lobos» de hierro (lupi ferrei) utilizados en 207 por los defensores de Orongis, en la Alta Andalucía, para repeler los intentos de escalada de los romanos (Liv., XXVIII, 3, 6-7). Ahora bien, estos ustensilios muy sencillos (aunque seguramente muy eficaces) no son equiparables con las auténticas máquinas de los ejércitos romanos y púnicos, y no hay duda de que fueron conocidos en Iberia, como en el resto del Mediterráneo, desde mucho tiempo antes de la difusión de los innovaciones militares helenísti$\operatorname{cas}^{10}$. Por otra parte, la tantas veces citada falárica incendiaria de Sagunto, descrita en detalle por Tito Livio (XXI, 8, 10), es una simple adaptación de una lanza que los iberos utilizaban normalmente, sin fuego, en combates en campo raso, según indicaciones del mismo autor $(\mathrm{XXXIV}, 14,10)^{11}$.

Sagunto según Tito Livio XXI. Comentarios sobre aspectos técnicos y estratégicos», Gerión, 13, 1995, p. $241-274$ (con algunas interpretaciones discutibles).

6 Entiendo esta palabra en su sentido etimológico, es decir: ciencia del asedio. La defensa de las plazas fortificadas no entra en el campo de la poliorcética.

7 En Liv. XXII, 21, 7, XXIII, 26, 5 y XXIII, 27, 2, las expresiones ui expugnare y ui capere, «tomar por la fuerza», son demasiado imprecisas: pueden aludir tanto a un asedio breve terminado por un asalto como a un asalto sin preparación. Además, en el primer caso son celtíberos los que tria oppida ui expugnant.

8 Tito Livio es el único historiador antiguo del que se puede sacar algun provecho sobre estas cuestiones. No entiendo lo que pudo llevar a F. Gracia a decir que el relato de Polibio sobre el asedio de Sagunto es un documento «explícito» sobre «técnicas de defensa contra ejércitos dotados de máquinas de guerra», añadiendo que «poner reservas a la veracidad del texto de Polibio partiendo de la base que el autor pudo incluir en la narración elementos propios de la estrategia de asedio romana supone cuestionar la totalidad del relato de Polibio» (p. 157). Vuelvo a leer el texto de Polibio, y encuentro lo siguiente: «Aníbal estableció su campo cerca [de la ciudad] y se dedicó activamente al asedio» (III, 17, 4) y, «finalmente tomó la ciudad por la fuerza a cabo de ocho meses» (III, 17, 9). Esto es todo.

9 Patefacta repente porta uniuersi in eos erumpunt (Liv., XXXIV, 20, 6-7).

10 En este sentido, ya no estoy tan seguro que la presencia de una guarnición cartaginesa en Orongis (punicum praesidium) haya podido ser la causa del uso de estos artefactos, a pesar del sugerente paralelo con los harpagones de Tiro y de Cartago (referencias en Fortif. Ib., p. 257).

11 Sobre el problema planteado por la discrepancia entre la descripción de Livio (hasta de pino cilíndrica, hierro de tres pies de largo y de sección cuadrada) y lo que se sabe de las lanzas ibéricas, véase Fortif. Ib., p. 260. Mi hipótesis es que la descripción detallada del arma es un elemento añadido al relato análistico original por Livio o por una de sus fuentes ; el autor de esta descripción se habría basado en la forma de la única falárica que conocía, es decir la itálica (falarica es una voz etrusca), probablemente una lanza muy parecida al pilum. Ver con respecto a la falarica el análisis detallado de F. Quesada, El armamento ibérico..., Monographies Instrumentum 3, Montagnac 1997, p. 334-343. 
Para terminar con este apartado, las supuestas evidencias del uso de una artillería defensiva en Sagunto y Atanagro (según F. Gracia, p. 141) no resisten a un examen pormenorizado de los textos. La única fuente existente sobre la «balista focea» de Sagunto es Silio Itálico (Punica, I, 334-337). Como queda demostrado en el excelente comentario de F. Spaltenstein $^{12}$, este poeta no se puede considerar bajo ningun aspecto como una fuente histórica fiable, a menos que otros autores confirmen su testimonio ${ }^{13}$. La balista focea de Silio es una invención sin pies ni cabeza, fruto de un trabajo de distorsión poética basado en la hipérbole. El resultado es totalmente inverosímil, pues se trata ni más ni menos que de una máquina capaz de lanzar alternativamente troncos enteros y rocas, funcionando al mismo tiempo como litóbolo y como oxíbeles! ${ }^{14}$. Lo mismo pasa con la falárica gigante que necesita «muchos brazos» para ser lanzada (Punica, I, 350-357): no hace falta buscar fuentes analísticas ajenas a la tradición liviana para descripciones de este calibre; no es otra cosa que una transmutación fantástica de la lanza descrita por Tito Livio.

La mención de Atanagro ${ }^{15}$ se debe probablemente a una confusión con otro episodio. Tito Livio no da ningun detalle sobre el asedio de la capital de los ilergetes ${ }^{16}$, pero en las líneas siguientes habla de las durísimas condiciones climáticas que dificultaron el asedio del urbs Ausetanorum, hasta tal punto que la nieve impidió que las antorchas o dardos incendiarios (ignis) lanzados de vez en cuando por los defensores provocasen el incendio de las protecciones de madera de los romanos (plutei y uineae $)^{17}$. Supongo que es este episodio al que alude F. Gracia; sin embargo, la frase de Tito Livio no da indicio alguno para pensar que la distancia entre la muralla y el cerco romano fuese tan grande como para hacer necesario el uso de máquinas.

Como consecuencia inevitable de la desigualdad táctica y tecnológica que se acaba de exponer, todos los asedios descritos - salvo las notables excepciones del urbs Ausetanorum y de Sagunto- se terminaron en muy poco tiempo con la toma del oppidum ibérico, sin que los romanos o los cartagineses tuviesen que utilizar máquinas sofisticadas ni contar con los efectos el hambre.

Si pasamos ahora de las fuentes literarias al registro arqueológico, es forzoso constatar que hasta ahora no se ha encontrado en el mundo ibérico prerromano ningun vestigio arqueológico relacionado con técnicas poliorcéticas avanzadas, cualesquiera que fueran: rampas de asalto, túneles de zapadores, cabezas metálicas de arietes, proyectiles pesados o elementos mecánicos atribuibles a máquinas arrojadizas (Fortif. ib., p. 255).

Quedan pues, en último lugar, las informaciones proporcionadas por las propias fortificaciones, es decir, eventuales pruebas de una adaptación de la arquitectura militar a las nuevas tácticas y técnicas de asedio. Veámos los cuatro elementos que F. Gracia presenta como evidencias a favor de esta adaptación.

1) Las técnicas de construcción con abundante relleno de tierra o con adobes, porque resisten mejor a los golpes de los proyectiles y de los arietes (p. 150-151). Cierto es que la relativa plasticidad de este tipo de construcciones puede resultar efectiva para absorber los golpes, sin embargo son técnicas muy antiguas, empleadas desde la Edad del Bronce, y fue precisamente a partir del siglo II — momento en el que sabemos a

\footnotetext{
12 F. Spaltenstein, Commentaire des Punica de Silius Italicus (livres 1 à 8), Genève, 1986.

13 F. Gracia es consciente del peligro de anacronismo que conlleva la utilización de Silio Itálico («la cita puede ser apócrifa», p. 141), sin embargo no saca claramente las consecuencias.

14 Spaltenstein, op. cit., p. 57 ; Fortif. Ib., p. 249 y 254.

15 «La distancia a la que llegan los proyectiles lanzados por los defensores de Atanagro en el 218 a.C. indicaría asimismo el empleo de máquinas por los defensores de la ciudad» (p. 141).

16 Scipio (...) Atanagrum urbem, quae caput eius populi erat, circumsedit, intraque dies paucos pluribus quam ante obsidibus imperatis Ilergetes pecunia etiam multatos in ius dicionemque recepit (XXI, 61, 6-7).

17 Triginta dies obsidio fuit, per quos raro unquam nix minus quattuor pedes alta iacuit adeoque pluteos ac uineas Romanorum operuerat ut ea sola ignibus aliquotiens coniectis ab hoste etiam tutamentum fuerit (XXI, 61, 10).
} 
ciencia cierta que las máquinas de guerra están presentes en España— cuando su uso empezó a decaer.

2) Las torres pentagonales del Castellet de Banyoles (Tivissa) y de La Serreta (Alcoy) comprobarían la existencia de una artillería ibérica, porque sus frentes angulosos estarían diseñados para provocar «un efecto de deflación del proyectil» (p. 150). De hecho, sabemos que esta propiedad mecánica de las torres pentagonales fue conocida y aprovechada por los ingenieros militares helenísticos. Sin embargo, es fácil constatar que la eficacia defensiva de las torres de Tivissa resulta singularmente mermada por la debilidad de las murallas adyacentes y, sobre todo, porque la disposición convergente de sus ejes hacía imposible la vigilancia del camino de acceso en frente de la única puerta del oppidum (Fortif. Ib., p. 217 y 417). Semejantes descuidos en la planificación arquitectónica de las defensas del sector de acceso dan la impresión que los valores de ostentación y prestigio, tan evidentes en las torres de Tivissa, tuvieron prelación sobre los requisitos de la técnica militar. En este contexto, no creo que los cálculos balísticos jugaron papel alguno en los planes del arquitectecto de Tivissa. Por otra parte, y como apunte a la figura 2 de F. Gracia (p. 159), recordaré que existe une diferencia importante entre las torres de Tivissa y sus eventuales protótipos griegos, en cuanto al esquema geométrico que rige su trazado ${ }^{18}$. Las torres pentagonales helenísticas tenían como base un triángulo rectángulo cuya hipotenusa determina la anchura de la torre, razón por la cual su punta forma un ángulo recto ${ }^{19}$. En cambio, la base geométrica de las torres de Tivissa es un triángulo equilátero, con ángulo agudo de $60^{\circ}$ en la punta. Sin negar el influjo formal ejercido por algun lejano modelo helenístico, estoy convencido de que estas torres ilercavones son el resultado de un proceso de recreación profundamente original, en el que poco o nada se conservó de los conceptos teóricos que originaron la invención griega de la torre pentagonal.

Muy distinto es el caso de La Serreta. Su torre no tiene nada que ver con el tipo pentagonal helenístico, ni con las torres de Tivissa. Tanto el plano como la reconstrucción propuesta por sus excavadores muestran que se trata de una torre trapezoidal irregular, con la peculiaridad añadida de una zapata o cimentación redondeada que rebasa su frente ${ }^{20}$.

3) Las grandes torres rectangulares (de simple o doble cámara) de Ullastret, Turó del Montgròs y Les Toixoneres «responden perfectamente a las descripciones clásicas sobre la construcción de casamatas de tiro» (F. Gracia, p. 142). Sin llegar a ser tan afirmativo, me he preguntado yo también si la innovación que representa este tipo de torres de gran tamaño pudiera tener alguna relación con la aparición de una artillería de tipo helenística (Fortif. Ib., p. 255-256). El problema está en la cronología. En Grecia, no hay que olvidar que la adaptación de las torres a la nueva maquinaria de asedio es un fenómeno que se fecha hacia finales del siglo IV ${ }^{21}$. Las torres catalanas aludidas por F. Gracia son del siglo IV, lo que hace muy difícil una interpretación en este sentido. Mejor candidato sería la gran torre de Torreparedones (Baena-Castro del Río, Córdoba), construida entre finales del siglo IV y principios del III y cuya metrología apunta hacia modelos púnicos 22 .

18 P. Moret, «'Rostros de piedra'. Sobre la racionalidad del proyecto arquitectónico de las fortificaciones urbanas ibéricas», en Los Iberos, príncipes de Occidente (Congreso internacional, Barcelona, 12-14 de marzo de 1998), Barcelona, 1998, p. 89.

19 P. Brun, «Les fortifications d'Hyllarima, Philon de Byzance et Pleistarchos», Revue des Etudes Anciennes, 96 (12), 1994, p. 193-204, con la bibliografía anterior.

20 M. Olcina et alii, «Nuevas aportaciones a la evolución de la ciudad ibérica: el ejemplo de La Serreta», en Los Iberos, príncipes de Occidente (Congreso internacional, Barcelona, 12-14 de marzo de 1998), Barcelona, 1998, p. 41 y fig. 3.

21 Y. Garlan, Recherches de poliorcétique grecque, París, 1974, p. 257-262.

22 P. Moret, «Rostros de piedra...», art. cit., p. 90. 
4) Pasaré más rapidamente sobre el tema de los fosos y de los antemuros ${ }^{23}$. Todas las defensas avanzadas que se conocen en el mundo ibérico se situan a muy poca distancia de la muralla; por consiguiente, no tenían utilidad alguna contra el eventual uso de una artillería de largo alcance.

En conclusión, la propuesta de F. Gracia relativa a la existencia de máquinas de asedio en el mundo indígena debe ser tomada por lo que es: una hipótesis no comprobada. Ahora bien, por ello no voy a negar la posibilidad del conocimiento de técnicas poliorcéticas relativamente avanzadas en ciertos contextos peninsulares, como por ejemplo el hinterland de Ampurias, parte del Sureste y la Turdetania. Considero incluso que este conocimiento es altamente probable, dada la intensidad de los contactos entre estos sectores ibéricos y la esfera colonial durante el siglo III. Pero dudo que estas experiencias marginales hayan tenido una influencia significativa sobre la evolución de la arquitectura defensiva en el resto del mundo ibérico. Topamos aquí con la cuestión esencial: ¿de qué iberos estamos hablando, cuando disertamos en términos muy generales, y a veces muy tajantes, sobre las fortificaciones ibéricas o cualquier otro tema arqueológico?

En el citado artículo, F. Gracia hace una serie de afirmaciones sobres los conocimientos militares y poliorcéticos de los iberos, pero cuesta saber de qué iberos se trata. No delimita su territorio ni define sus rasgos culturales ${ }^{24}$. ¿Se limita el corpus estudiado a los diez yacimientos arqueológicos mencionados en el artículo (Ullastret, Ampurias, Calafell, Tivissa, Turó del Montgròs, Burriac, Els Vilars, La Serreta, La Picola y Capote)? ¿Con qué criterios se hizo esta selección? No nos da la clave ${ }^{25}$.

En un tema como éste hay que elegir entre dos caminos. El primero: estudiar de forma específica el tema de los influjos griegos en la arquitectura defensiva ibérica, ciñéndose al puñado de yacimientos excepcionales, encabezados por Ullastret, en los que se detectan, en mayor o menor medida, tales influjos. Es un enfoque perfectamente válido ${ }^{26}$, siempre y cuando se deja bien claro que lo de que se trata es una parte muy pequeña del complejo mundo de las fortificaciones ibéricas. Al olvidar esta realidad, uno corre el riesgo de convertir la cultura ibérica en una entelequia desencarnada y gravemente sesgada.

La otra opción consiste en ampliar la mirada al conjunto de las fortificaciones conocidas en el ámbito ibérico, y en este caso surge la necesidad de analizar decenas, por no decir centenares de casos, cada uno con sus peculiaridades, teniendo en cuenta la existencia de varias áreas culturales, con personalidades propias y ritmos evolutivos dispares; en otras palabras: arrostrar la terca e infinitamente matizada complejidad de los hechos.

PIERRE MORET

Unité Toulousaine d'Archéologie et d'Histoire - CNRS, UMR 5608.

23 Recopilación de los datos conocidos en Fortif. Ib., p. 125-131. Excavaciones y prospecciones posteriores a la redacción de esta síntesis aportan algunos datos más, especialmente en Els Vilars (fase III), Santa Pola, Pico de los Ajos y Ullastret, pero no modifican el panorama general. El uso indiscriminado de la palabra griega proteichisma (¡neutra, no femenina!) esconde realidades muy diversas, con vestigios a veces difíciles de fechar y de reconstruir.

24 Algunos ejemplos pertenecen al mundo hispanocéltico (p. 136: celtíberos; p. 138: Salamanca; p. 141: Capote en Extremadura).

25 Se puede notar que de los diez yacimientos citados, siete son catalanes, y ninguno es andaluz (cifras que contrastan con las de los ejemplos sacados de las fuentes literarias).

26 Como ejemplo reciente véase H. Müller, «Beobachtungen an Befestigungsanlagen in Katalonien. Elemente griechischer Befestigungstechnik in Emporion, Ullastret und Tivissa», MM, 37, 1996, p. 86-102. 